\title{
Geophysical Contribution for the Determination of Aquifer Properties in Memve Ele, South Cameroon
}

\author{
Harlin L. Ekoro Nkoungou ${ }^{1}$, Philippe Njandjock Nouck ${ }^{1,2 *}$, Dieudonné Bisso ${ }^{3,4}$, \\ Stéphane Assembe ${ }^{1}$, Eliézer Manguelle Dicoum ${ }^{1}$ \\ ${ }^{1}$ Department of Physics, Faculty of Science, University of Yaounde I, Yaounde, Cameroon \\ ${ }^{2}$ International Institute for Water and Environmental Engineering, Ouagadougou, Burkina-Faso \\ ${ }^{3}$ Department of Earth Sciences, Faculty of Science, University of Yaounde I, Yaounde, Cameroon \\ ${ }^{4}$ Memve Ele Dam Project, Yaounde, Cameroon \\ Email: *pnnouck@yahoo.com
}

Received July 31, 2012; revised August 31, 2012; accepted September 29, 2012

\begin{abstract}
This article aims to localise aquifer and to estimate hydraulic parameters such as transmissivity and tranverse resistance in the Memve Ele dam site $\left(26.35 \mathrm{~km}^{2}\right)$ in South-Cameroon region, using audiomagnetotelluric (AMT) method. For this purpose, resistivity data are collected at twenty-two measurement stations distributed along two perpendicular profiles in the study area. The sounding curves of phase and impedance are modelled and interpreted. The geological models and geoelectrical sections are also provided. The transverse resistivity and transmissivity field maps are plotted. The audiomagnetotellurics insights have been compared with boreholes. All these results allow us to localise the area which may be suitable to set up monitoring wells.
\end{abstract}

Keywords: Hydraulic Parameters; Aquifer; Audio-Magnetotelluric Method; Sounding Curves; Memve Ele

\section{Introduction}

Construction of great structures as dams implies delocalization of populations from the targeted area. This is the case of the Memve-Ele dam site project. The Choice of the rehousing zones depends both on the qualitative and the quantitative availability of water. Conventionally, these parameters are estimated through pumping tests carried out on water wells. Few boreholes are available and carrying out pumping tests at several sites may be costly and time consuming. The application of geophysical methods presents a cost-effective and efficient alternative to estimate aquifer parameters [1]. This paper discusses the results obtained from twenty-two soundings carried out through two perpendicular profiles using the audiomagnetotelluric (AMT) method. The survey consists of a quite fast and versatile geophysical investigation (AMT) technique applied to environmental studies focused on groundwater, along with correlated mechanical drillings [2]. The study was conducted in the Memve Ele dam site area. The main objectives of these geophysical surveys were to characterize aquifer lithology and main hydraulic parameters, to describe the aquifer nature, characterize the optimal drilling zone and the potential pollution risk zone.

\footnotetext{
${ }^{*}$ Corresponding author.
}

\section{Geology}

The Memve Ele site, in the lower reaches of the Ntem basin, is located between latitudes $\mathrm{N} 02^{\circ} 15^{\prime}$ and $\mathrm{N} 02^{\circ} 30^{\prime}$, $\mathrm{E} 10^{\circ} 15^{\prime}$ and $\mathrm{E} 10^{\circ} 30^{\prime}$. Its catchment area is $26,350 \mathrm{~km}^{2}$. At this site the Memve Ele waterfalls with about $35 \mathrm{~m}$ head offer favourite site for a hydroelectric power plant development. The geologic background suggests that the formations encountered are widely composed of pyroxene hornblende. These are essentially gneisseses and granitic gneisses that come from metamorphosed precambrian sedimentary rocks [3]. The geological map of the dam site is shown in Figure 1. The site's geological feature is characterized by the development and distribution of faults and schiscosity in the same direction [4]. The result of seismicity analysis shows that only three events had affected the site during past some 300 years [3]. The area's earthquaque coefficient $(k)$ for the return period of 100 years is given by $k=0.001 \mathrm{G}$. There is no geological evidence regarding the active faults that results from investigations.

\section{Methodology}

\subsection{Data Acquisition}

The acquisition of data is based on the magnetotelluric method principle [5] which mainly measures the apparent 


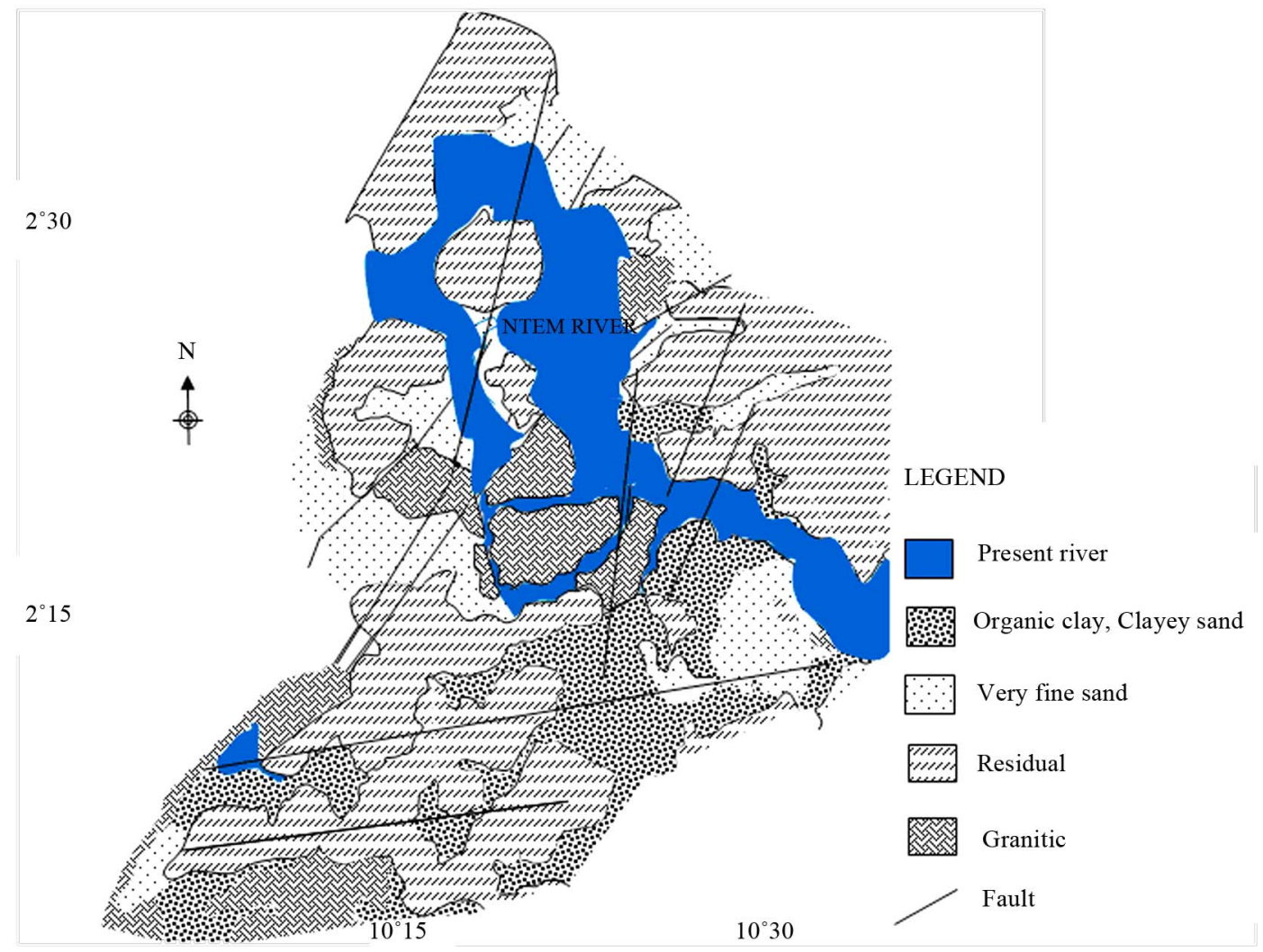

Figure 1. Geologic map of Menvele-Ele area [3], modified.

resistivity of physical environments through its fundamental relationship (1):

$$
\rho_{a}=0.2 T\left|\frac{E}{H}\right|^{2}
$$

The equipment used is a resistivity-meter ECA 540. This resistivity-meter is a scalar type composed of two identical selective measuring outlets, associated to an acquisition and calculation system that uses a microprocessor. The data sets were collected into two perpendicular directions (N-S and E-W) with a resistivity-meter measuring the apparent resistivity $\rho_{\perp}$ and $\rho||$ following respectively N-S and E-W directions. The apparent resistivity obtained in each direction has permitted to calculate the mean apparent resistivity $\left(\rho_{a}\right)$ or impedance defined by (2)

$$
\rho_{a}=\sqrt{\left(\rho_{\perp} \times \rho||\right)}
$$

This constitutes the analytic data. The value of phase $(\varphi)$ have been determined by $(3),[2,6]$

$$
\varphi=\frac{\pi}{2}-\frac{\pi}{4}\left[1+\frac{\mathrm{d} \ln \rho_{a}}{\mathrm{~d} \ln T}\right]
$$

where, $\rho$ and $T$ are respectively the apparent resistivity and period.

Resistivity and phase values were inversed and mo- delled with the program developed by [1].

\subsection{Hydraulic Parameters}

In stratified conductors' theories, some parameters are fundamentally important both in the interpretation and understanding of the geoelectrical model. These parameters are related to different combinations of the thickness and resistivity of each geoelectrical layer in the model.

For a sequence of $n$ horizontal, homogeneous and isotropic layers of resistivity $\rho_{i}$ and thickness $h_{i}$, the DarZarouck parameters (4) et (5) (longitudinal conductance $\mathrm{S}$ and transverse resistance $\mathrm{T}$ ) are defined respectively $[7,8]$ on a purely empirical basis:

$$
S_{i}=\sum_{i}^{n} \frac{h_{i}}{\rho_{i}} \text { in (Siemens) }
$$

and

$$
T_{i}=\sum_{i}^{n} \rho_{i} * h_{i} \text { in }\left(\mathrm{ohm} \cdot \mathrm{m}^{2}\right)
$$

It can also be admitted that the transmissivity of an aquifer is directly proportional to its transverse resistance. By the other way, the protective capacity of the overburden could be considered as being proportional to the longitudinal Conductance. The hydraulic parameters are shown in Table 1. 


\section{Results and Discussion}

\subsection{Sounding Curves}

The curves resulting from the whole soundings presented a five layered earth's model whose ranges of values led us to a three group's classification according to the covering resistivity values' ranges and drillings results. The low covering resistivity values $(100-200 \Omega \cdot \mathrm{m})$ have been obtained at stations $\mathrm{A} 1$ and $\mathrm{A} 4$, the middle covering values of resistivity $(200-300 \Omega \cdot \mathrm{m})$ have been obtained at $\mathrm{A} 2, \mathrm{~A} 3, \mathrm{~A} 5, \mathrm{~B} 1$ and $\mathrm{B} 2$ while the high resistivity val- ues (300 - $1000 \Omega \cdot \mathrm{m})$ have been obtained at stations B3, B4 and B5 (Figures 2 to 4 and Table 2).

\subsection{Geoelectrical Sections}

Gathering the sounding curves, we delineate four resistivity values' ranges suggesting a four layered earth model. Moreover, a strong gradient of resistivity has been observed between the third and the fourth layer. These layers have been assumed by comparing resistivity values' ranges with data in Table 3. From the observation of

Table 1. Hydraulic parameters.

\begin{tabular}{|c|c|c|c|c|c|c|}
\hline Profile & Station & Aquifer Deep (m) & Aquifer Resistivity & Aquifer Thickness & Longitudinal Conductance & Transverse Resistance \\
\hline \multirow{5}{*}{ A } & $\mathrm{A} 1$ & 51 & 38 & 9 & 0.24 & 342 \\
\hline & $\mathrm{A} 2$ & 52 & 50 & 13 & 0.26 & 650 \\
\hline & A3 & 51 & 62 & 20 & 0.32 & 1240 \\
\hline & A4 & 52 & 43 & 15 & 0.35 & 645 \\
\hline & A5 & 44 & 58 & 15 & 0.26 & 870 \\
\hline \multirow{5}{*}{$\mathrm{B}$} & B1 & 53 & 52 & 13 & 0.25 & 676 \\
\hline & B2 & 49 & 60 & 17 & 0.28 & 1020 \\
\hline & B3 & 54 & 52 & 12 & 0.23 & 624 \\
\hline & B4 & 46 & 79 & 19 & 0.24 & 1501 \\
\hline & B5 & 54 & 60 & 14 & 0.23 & 840 \\
\hline
\end{tabular}
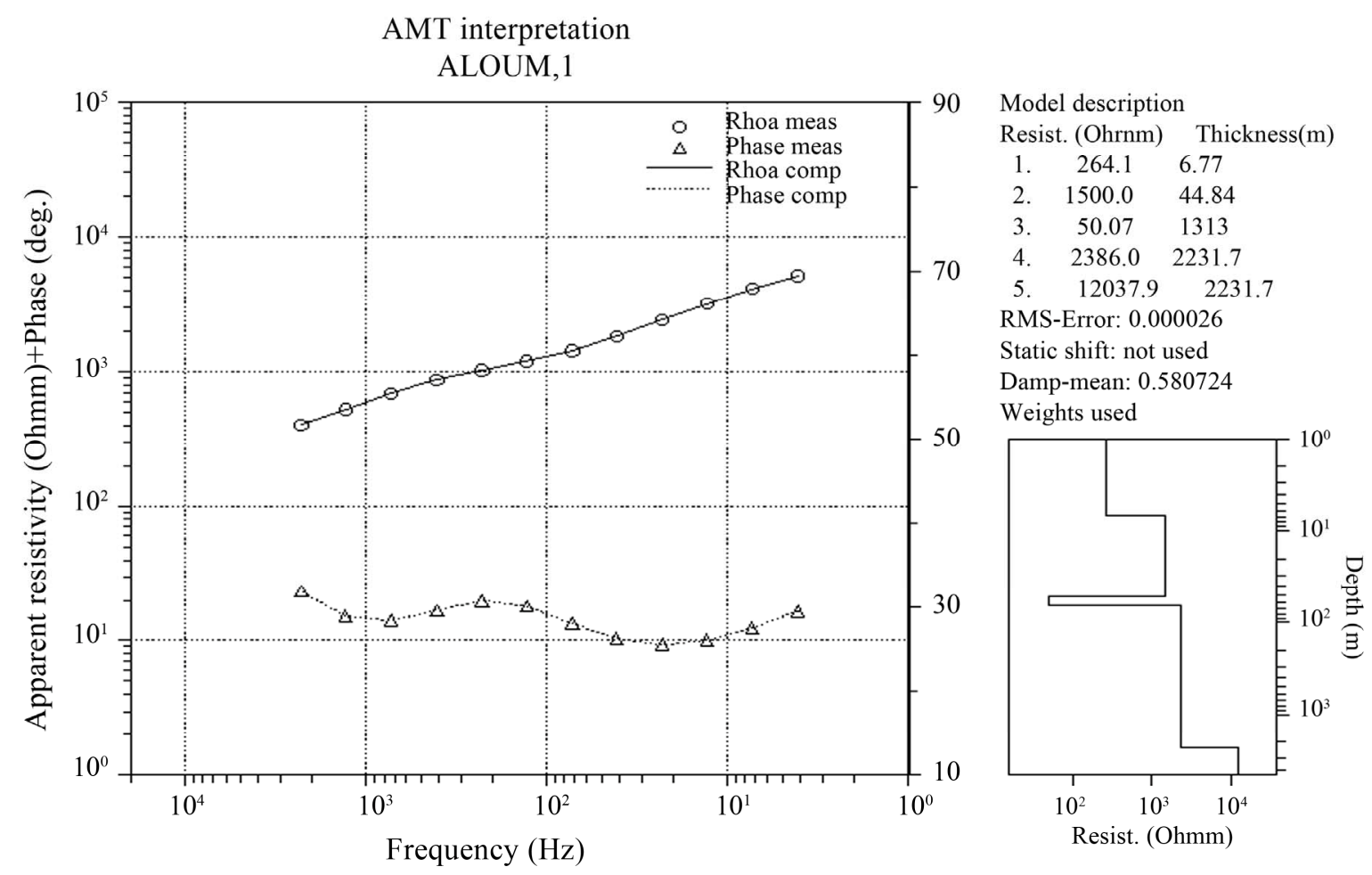

Figure 2. A2 sounding curves (Aloum 1). 


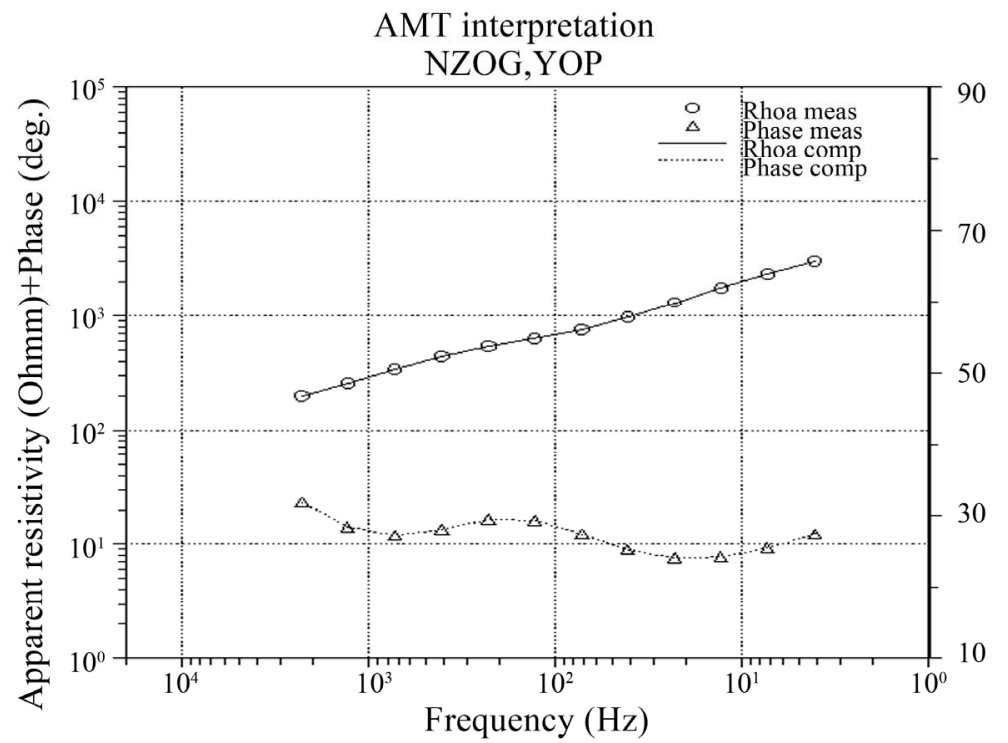

Figure 3. A4 sounding curves (Nzog Yop).

AMT interpretation

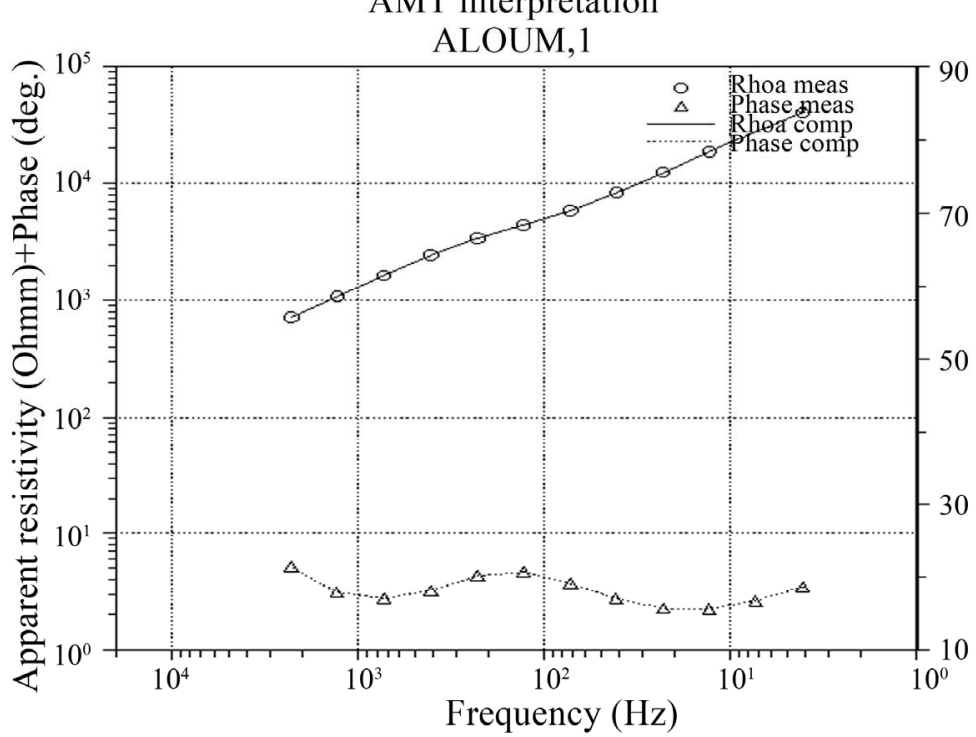

Model description

Resist. (Ohrnm) Thickness(m)

1. $131.0 \quad 16.80$

2. $\quad 964.0 \quad 34.51$

3. $42.60 \quad 14.60$

$\begin{array}{lll}\text { 4. } & 1429.3 & 1859.1\end{array}$

5. 8262.5

RMS-Error: 0.000055

Static shift: not used

Damp-mean: 0.854485

Weights used

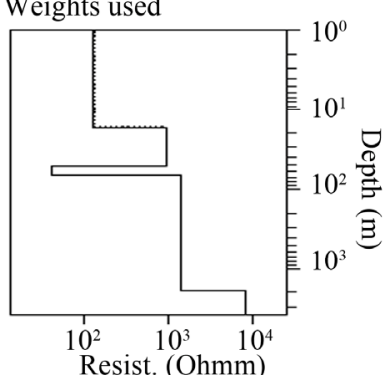

Model description

Resist. (Ohrnm) Thickness(m)

$\begin{array}{lll}\text { 1. } & 696.7 & 17.51\end{array}$

2. $\quad 3231.1 \quad 36.36$

3. $52.38 \quad 11.66$

4. $\quad 18811.1 \quad 8833.1$

5. 241377.6

RMS-Error: 0.000760

Static shift: not used

Damp-mean: 0.558181

Weights used

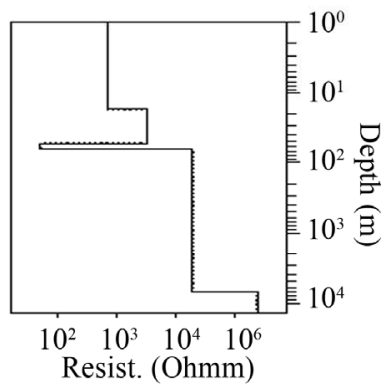

Figure 4. B5 sounding curves (E. P. Nnemeyong).

Table 2. Thicknesses and resistivity's values resulting from soundings curves.

\begin{tabular}{ccccccccccc}
\hline \multirow{2}{*}{ Layer } & \multicolumn{2}{c}{ A1 } & \multicolumn{2}{c}{ A2 } & \multicolumn{2}{c}{ A3 } & \multicolumn{2}{c}{ A4 } & \multicolumn{2}{c}{ A5 } \\
\cline { 2 - 11 } & $\rho$ & $h$ & $\rho$ & $h$ & $\rho$ & $h$ & $\rho$ & $h$ & $\rho$ & $h$ \\
\hline 1 & 164 & 8 & 264 & 7 & 213 & 7 & 131 & 17 & 259 & 8 \\
2 & 2079 & 43 & 1500 & 45 & 2267 & 44 & 984 & 35 & 1639 & 36 \\
3 & 38 & 9 & 50 & 13 & 62 & 20 & 43 & 15 & 58 & 15 \\
4 & 2955 & 4821 & 2386 & 2232 & 2761 & 2372 & 2429 & 1859 & 2956 & 4138
\end{tabular}

\begin{tabular}{ccccccccccc}
\hline \multirow{2}{*}{ Layer } & \multicolumn{2}{c}{ B1 } & \multicolumn{2}{c}{ B2 } & \multicolumn{2}{c}{ B3 } & \multicolumn{2}{c}{ B4 } & \multicolumn{2}{c}{ B5 } \\
\cline { 2 - 11 } & $\rho$ & $h$ & $\rho$ & $h$ & $\rho$ & $h$ & $\rho$ & $h$ & $\rho$ & $h$ \\
\hline 1 & 246 & 16 & 246 & 21 & 696 & 18 & 461 & 19 & 350 & 7 \\
2 & 2539 & 37 & 2181 & 28 & 3231 & 36 & 5867 & 27 & 3325 & 47 \\
3 & 52 & 13 & 60 & 17 & 52 & 12 & 79 & 19 & 60 & 14 \\
4 & 2014 & 4157 & 2901 & 3106 & 2833 & 6833 & 2751 & 5499 & 2281 & 2508 \\
\hline
\end{tabular}

Table 3. Geoelectrical model.

\begin{tabular}{cc}
\hline Lithology (prevalence) & Resistivity $(\Omega \cdot \mathrm{m})$ \\
\hline Captive aquifer & $40-100(\Omega \cdot \mathrm{m})$ \\
Lateritic clay & $100-200(\Omega \cdot \mathrm{m})$ \\
Organic deposit & $200-300(\Omega \cdot \mathrm{m})$ \\
Weathered granite-gneiss & $300-1000(\Omega \cdot \mathrm{m})$ \\
Granite-gneiss & $1000-10,000(\Omega \cdot \mathrm{m})$ \\
\hline
\end{tabular}

sounding curves obtained and mechanical drillings carried out in the study area, we obtained the following geoelectrical models (Figure 5) which are similar to those proposed by $[9,10]$. 


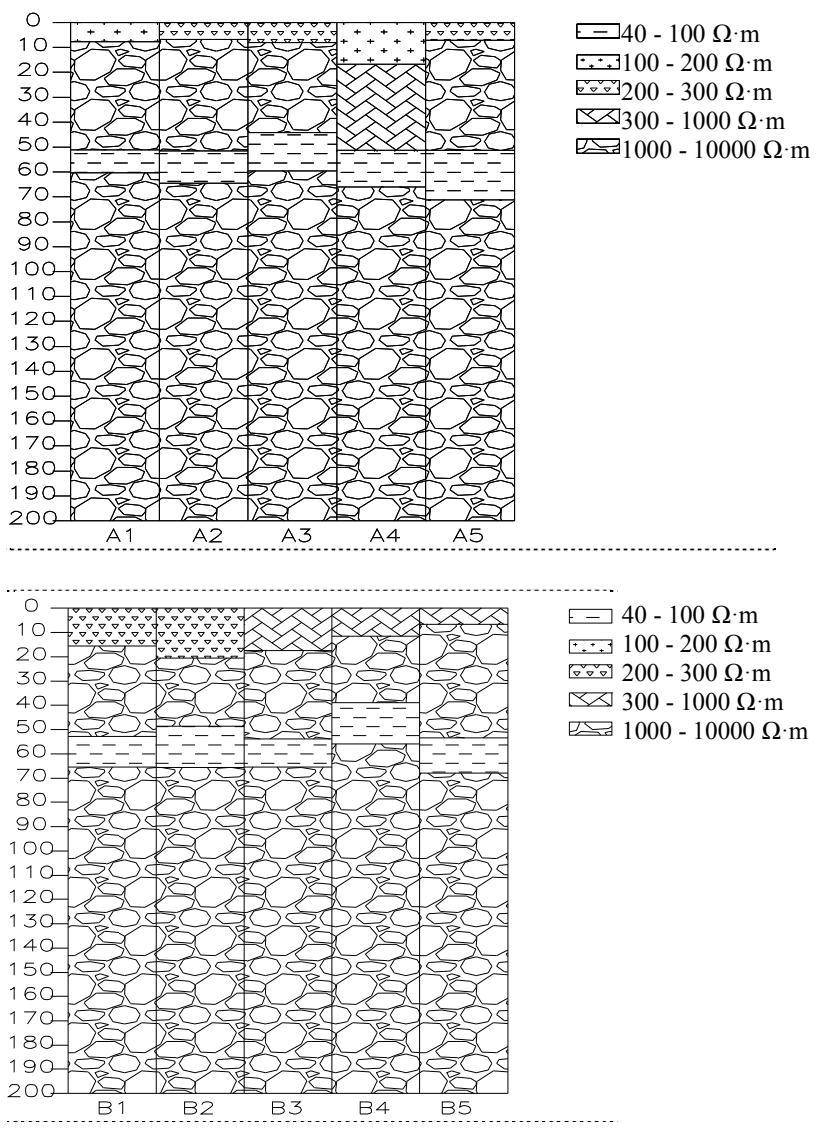

Figure 5. Geoelectrical sections.

\section{Structural Analysis}

\subsection{Aquifer Nature}

It arises that the lithology of the area is not homogeneous for the first two layers, due to old seismic movements. This is materialized by the in subsurface uplift of deep granite-gneisses in stations A 3 and A5 for the first profile, and between B2 and B5 for the second profile (Table 1). This near surface presence of deep granite-gneisses suggests that the area underwent intense tectonics after which the aquifer layer has been set up $[10,11]$. We assumed that the probable captive potable aquifer, which correspond to the third layer regarding its resistivity range (49 - $100 \Omega \cdot \mathrm{m}$ ) observed, was formed before seismic events. Moreover, the geological map highlights the presence of obvious faults at these places $[3,4]$ because seismic movements are noticeable on surface.

\subsection{Optimal Drilling Zone}

The analysis of the transmissivity field (Figure 7) estimated from transverse resistance (Figure 6) highlights the significant space variability of this parameter. The transmissive zones are located in the north-eastern part of the study area, between stations B3 and B5 where the geological map (Figure 1) shows a significant network of transverse faults; furthermore, these zones are marked by old seismic activities evidenced by the appearance of deep gneiss-granites at near subsurface. In addition, the average depth for both profiles can be accessed around 50 meters and the optimal drilling zone is not set in the future flooded zone.

\subsection{Aquifer protection}

Observation of conductivity's variation maps resulting from precedent data shows a weak variation ( 0.23 to 0.35 Siemens) of the ground water's conductivity in the area, inferring the quasi similar properties of the aquifer in this area. In addition, the samples collected by the KOEI Company did not present any physicochemical risk; this implies the inexistence of risky zones in this area.

\section{Conclusion}

The geophysical survey allowed us to obtain lithological identification and to characterize the conditions of the underground flow of the studied area. One ground wterunit was identified. A map of the transverse unit resistance illustrates the aquifer. In this map, the tendencies of

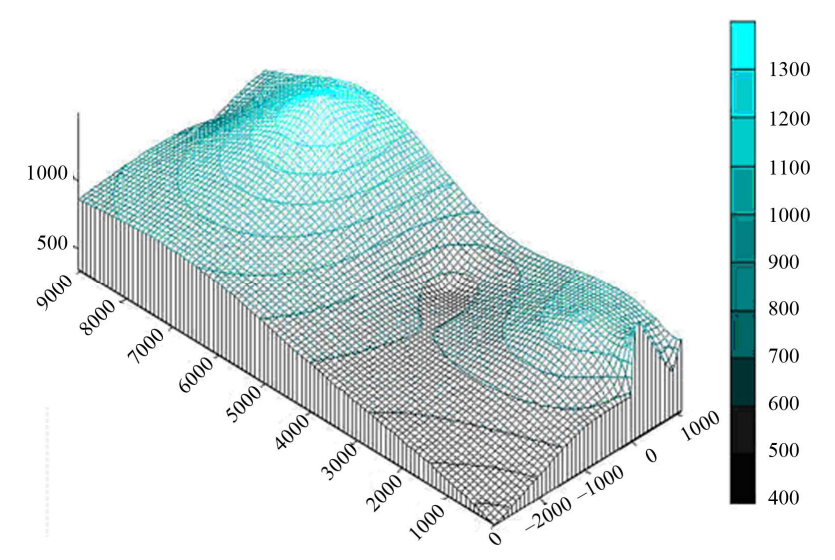

Figure 6. Transverse resistivity.

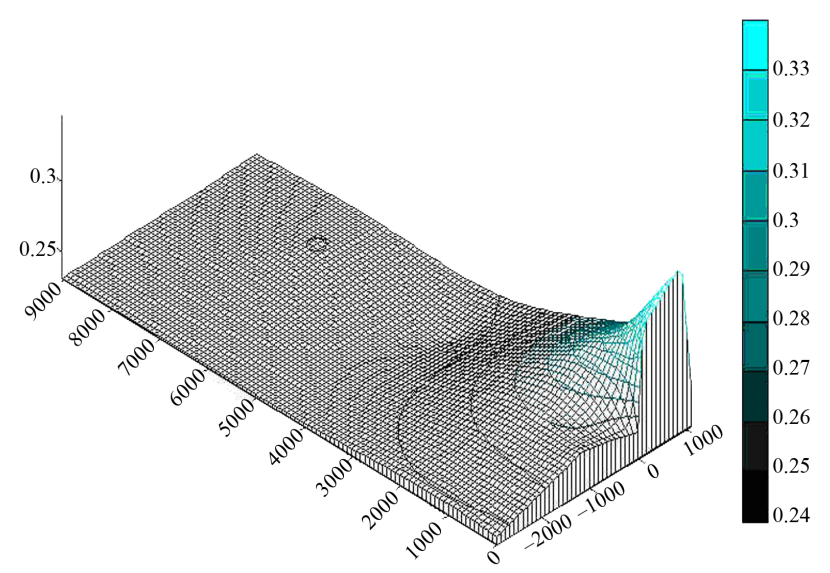

Figure 7. Transmissivity field map. 
high values of Transverse resistance can be associated with high transmissivity zones; hence, these zones are suggested for the installation of monitoring wells for the unconfined aquifer. The map of longitudinal conductance associated to hydrochemical result illustrates that, in the studied area, an eventual contamination risk zone was not identified.

\section{REFERENCES}

[1] M. Pirttijärvi, "Joint Interpretation of Electromagnetic and Geoelectrical Soundings Using 1-D Layered Earth Model," User's Guide to Version 1.3, Oulu, 2004, 48 p.

[2] P. Weidelt "The Inverse Problem of Geomagnetic Induction," Journal of Geophysics, Vol. 38, 1972, pp. 257-289.

[3] C. K. Nippon, "Faisability Study on Menve Ele Hydro Electric, Power Development Project," Final Report: AES-SONEL, Cameroon, 1993, 74 p.

[4] V. Caron, E. Ekomane, G. Mahieux, P. Moussango and E. Ndjeng, "The Mintom Formation (New): Sedimentology and Geochemistry of Neoproterozoic, Paralic Succession in South-East Cameroon," Journal of African Earth Sciences, Vol. 57, No. 4, 2009, pp. 367-385. doi:10.1016/j.jafrearsci.2009.11.006

[5] L. Cagniard, "Basic Theory of the Magneto Telluric Method of Geophysical Prospecting," Geophysics, Vol.
18, 1953, pp. 605-635. doi:10.1190/1.1437915

[6] Y. Ogawa, “On Two-Dimensional Modeling of Magnetotelluric Field Data," Geophysics Survey, Vol. 23, No. 2-3, 2002, pp. 251-273. doi:10.1023/A:1015021006018

[7] J. Asfahani, "Neogene Aquifer Properties Specified through the Interpretation of Electrical Sounding Data, Salamiyeh Region, Central Syria," Hydrological Processes, Vol. 21, 2007, pp. 2934-2943. doi:10.1002/hyp.6510

[8] A. A. R. Zohdy, P. G. Eaton and R. D. Mabey, "Application of Surface Geophysics to Groundwater Investigations," US Geological Survey Techniques of Water Water Resources investigations, Book 2, 1974.

[9] J. L. Meli'i, P. N. Njandjock and H. D. Gouet, "Magnetotelluric Method for Groundwater Exploration in Crystalline Basement Complex, Cameroon," Journal of Environmental Hydrology, Vol. 19, 2011, p. 16.

[10] J. L. Melii, P. N. Njandjock, A. F. Mbanga and E. Manguelle-Dicoum, "Spatial Analyses of Magnetotelluric Data in the Northern Part of Congo Craton in South Cameroon Region," Journal of Emerging Trends in Engineering and Applied, Vol. 3, N. 4, 2011, pp. 631-635.

[11] W. A. Teikeu, P. N. Njandjock, T. Ndougsa-Mbarga and T. C. Tabod, "Geoelectric Investigation for Groundwater Exploration in Yaoundé Area, Cameroon," International Journal of Geosciences, Vol. 3, 2012, pp. 640-649. 